\title{
IUGS CONSULTANTS ASSIST ASIAN DEVELOPMENT OF PETROLEUM DATA SYSTEMS
}

by

Jennifer L. Cook and Allen L. Clark

Background

\begin{abstract}
A successful ongoing joint project between CCOP and IUGS' Commission on Storage, Automatic Processing and Retrieval of Geological Data (COGEODATA) serves as a model for similar contractual services that can be offered by various IUGS groups of experts. This article outlines the specific tasks and activities undertaken by the COGEODATA consultants in SE Asia - in perspective of the region's overall program of hydrocarbon assessment.
\end{abstract}

The Committee for Co-ordination of Joint Prospecting for Mineral Resources in Asian Offshore Areas (usually identified as (COP) is an association of East Asian countries operating under the umbrella of the United Nations Economic and Social Commission for Asia and the Pacific (ESCAP). Its member countries are Indonesia, Singapore, Malaysia, Thailand, Vietnam, Papua New Guinea, Philippines, Japan, Korea, China, Kampuchea, and also the Trust Territory of the Pacific Islands. Representation in CCOP is through officials of the resources agencies (geological, mineral and petroleum), and a Secretariat, supported by funds from the United Nations Development Program (UNDP), is maintained in Bangkok, Thailand.

Since its inception in 1966, CCOP has stimulated considerable activity in offshore petroleum and mineral exploration in SE Asia, through its own efforts to publicize the geological potential of the region, through sponsorship of specific projects with the help of consultants, and through its participation in major international programs such as the International Decade of Ocean Exploration (the SEATAR Project) and the Circum-Pacific Map Project.

Recently, at the request of the oil-producing countries of SE Asia and through their ASEAN (Association of SE Asian
Nations) Council on Petroleum (ASCOPE), CCOP embarked on a program of investigation and assistance to SE Asian countries wishing to better understand, explore, and manage their hydrocarbon resources. In spite of the fact that these countries - in particular, Indonesia, Singapore, Malaysia, Thailand, and the Philippines - have fostered considerable oil company activity and a vast amount of data has accumulated from this activity, all of them wish to develop a better understanding of their petroleum potential through a program independent of the companies. They also want to develop their own capability to assess and manage their resources. For this reason ASCOPE turned to CCOP, and CCOP then requested the assistance of non-industry consultants who could work directly with their counterparts in the region.

The CCOP program of hydrocarbon assessment, which has evolved over the past two years, consists of several elements, some of which have involved IUGS directly. The countries recognized that before they could understand, assess, and manage their oil and gas resources, they had to bring order out of the masses of accumulated data files and materials, and to determine what sort of use could be made of the data. CCOP approached COGEODATA to help develop a petroleum data handling program, and through IUGS, organized a joint working group on petroleum data consisting of data systems consultants from the U.S.A. and Norway*, as well as one

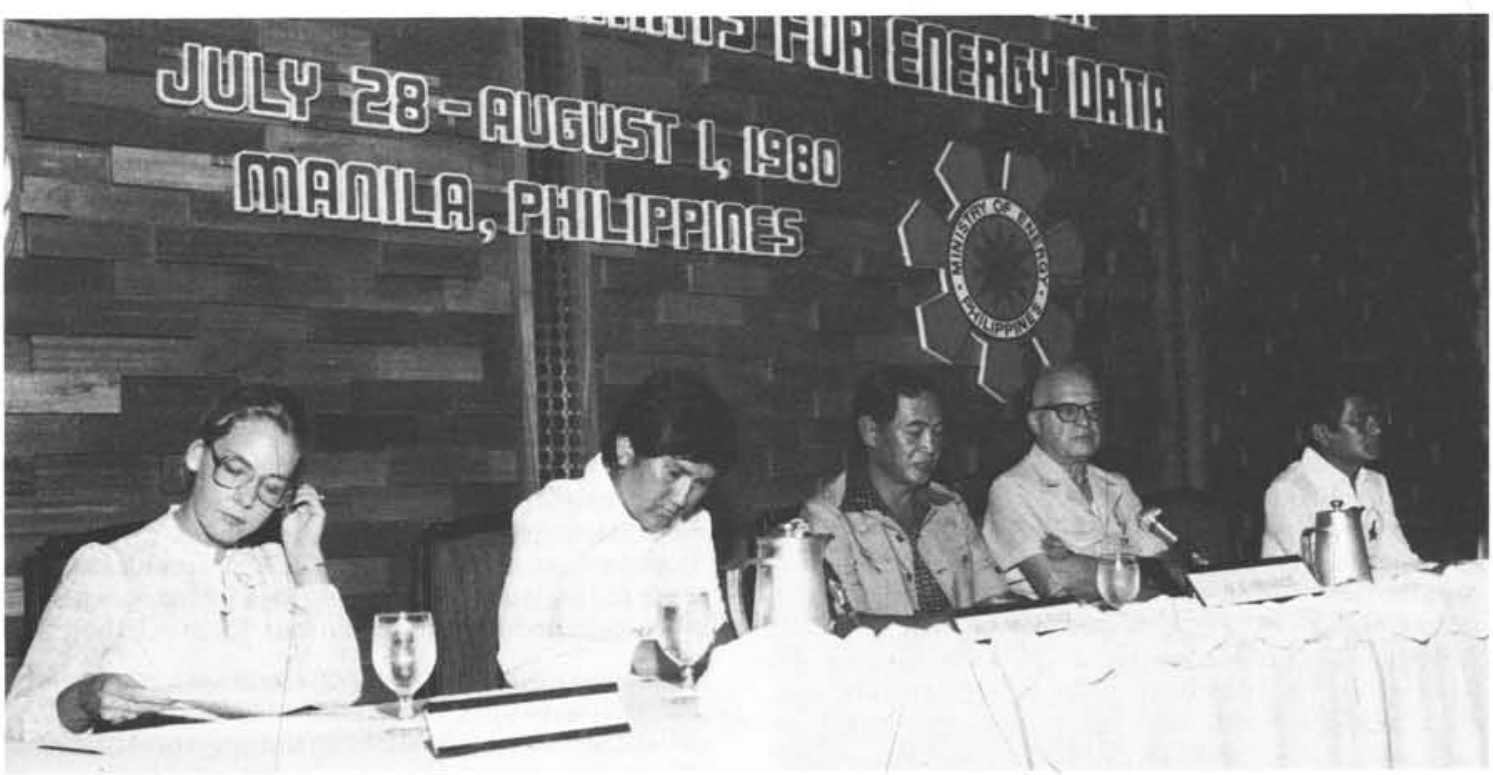

A workshop on petroleum data standardization and formats was held in Manila last year. From left: Jennifer Cook (U.S.A.); Atty. W.R. de la Paz, Director, Philippine Bureau of Energy Development; Hon. G.Z.Velasco, Philippine Minister of Energy; Dr. E. DuBois, CCOP; Dr. Salvidor Sali, Philippine National Oil Company.

* COGEODATA consultants were Dr. Richard Sinding-Larsen (Norway), Chairman of COGEODATA, Dr. Allen L. Clark and Ms. Jennifer L. Cook (U.S.A.). In November of 1980, Mr. Stein Salversen (Norway) joined the team.

EPISODES, Vol. 1981, No. 1. 
newber from ach partripating (Cop) member countr (eight of the twelve countries took part in the program).

During 1979 and 1980, four contracts were drawn up with COGEODATA covering the following activities:

a) Consultation with each of the CCOP member countries to determine general data handling, storage, and retrieval problems - which provided the basic information for a manual on petroleum data handling:

b) Analyzing in detail the $\mathrm{CCOP}$ member countries' physical data handling programs emphasizing long-term solutions to each respective country's problems - which led to specific country reports and recommendations.

\section{Problem Overview}

Each of the CCOP member countries had reached a different level of petroleum development, and accordingly, each had a variety of specific problems and corresponding needs. The COGEODATA/CCOP program attempted to address the full spectrum of the more important problems and to provide recommendations for dealing with their overall range.

The majority of oil and gas agencies receiving data in SE Asia had established mandatory archiving systems in support of national oil and gas programs. In most of the organizations, however, this activity had not been given high priority for various reasons, the more significant being:

- Some oil and gas agencies were established only recently, and attention had been focussed on problems of more immediate urgency than that of data management;

- Initially, the need for data management had been limited because the volume of data had been small;

Recent activities in exploration and development, along with increased analyses and national mandates for data submittals, resulted in a corresponding and rapid increase in data acquired;

There had been a general lack of trained personnel, particularly information specialists, to develop data management procedures;

- Management's failure to recognize the need to improve data management procedures had precluded development of programs in this area.

Information sources in the various oil and gas agencies ranged from core samples to tapes, reports, maps, telexes and microfilm - all of which had to be identified, catalogued and indexed in a standardized procedure. Indeed, as more and more data and information are generated and collected in SE Asia, there is an ever increasing need for adequate bibliographic control and archiving; the general problem of data management must be carefully analyzed so that all oil and gas data considered to be worth preserving are placed under some form of bibliographic control.

\section{The Program}

The importance of establishing national centers in each of the CCOP member countries for storing and retrieving proprietary petroleum data and geological samples received following increased regulation of petroleum activity had been stressed at the annual CCOP meetings as early as 1973. Toward this end, the Committee arranged in April of 1976 a seminar in Bandung, Indonesia on data collection, storage and retrieval, with particular reference to hydrocarbon exploration and development. The 15th session of CCOP in 1978, held in Singapore, acted on the recommendation of its Technical Advisory Group and early in 1979 established the ad hoc working group on petroleum data collection, storage, and retrieval. Support funds were delegated to the CCOP Project Office by the Government of Norway to finance travel expenses of the working group. Two contracts between IUGS (COGEODATA) and ESCAP (CCOP) were then set up covering the period January 1 to October 15, 1979.

Specifically, the consulting team was expected to perform the following in this time-frame:

- An appraisal and evaluation of the national needs of the CCOP countries concerning petroleum data collection, stor- age, and retrieval, that is: identification, indexing, storage, retrieval, dissemination, and utilization of data, either in a wholly manual mode, partly with computer assistance, or by means of comprehensive computer-based data systems;

- An evaluation of existing governmental and commercial data systems available in North America and Europe, which might be suitable for petroleum data collection, storage, and retrieval;

- An evaluation, in light of individual CCOP countries' needs, of the potential usefulness of available data systems for the countries' petroleum data activities. To conduct the program in a systematic manner, a standardized procedure of assessing the countries' petroleum data problems was adopted and applied, although the varying levels of data management in the respective countries made it difficult to apply the procedure unequivocably.

Essentially, it consisted of:

- Initial definition of current data problems such as data volumes, user environment, organizational environment, physical environment, as well as national and agency needs for data management;

- Definition and assessment of existing practices in the handling, storage, and retrieval of petroleum data;

- Detailed definition of the data types present, data volumes, reporting and acquisition procedures, data completeness, and data integrity;

- Development of a short-to intermediate-term analysis of data problems and an assessment of short- to long-range plans for data handling, storage, retrieval, and analysis;

- Development of alternate solutions to effective and efficient management of petroleum data, which would meet both current and anticipated needs.

In addition, the detailed evaluation procedure also identified several problem areas common (to varying extents) to all the oil and gas agencies. These problems are primarily a function of the stage of oil and gas development, the volumes of data, previous and existing data administration practices, and new needs for data and analyses. They include physical archiving, data files, geophysical data, data processing, and EDP administration (where specific needs were identified and action was called for to improve existing and future systems).

The recognition that effective organization and handling of oil and gas data support better decision-making in an organization has also led to the recognition that a new type of specialist is needed - the "information" or "da ta base" administrator - an individual charged with knowing (or being able to find out) exactly what is in his or her file, where each item of information is stored, how frequently it has been updated, and the implications of changing the routines used for bibliographic control and archiving of the data. It is also generally recognized that rather than being static, information is normally in a transition phase between its use in a dynamic process (exploration) and its longer term storage, as part of a national archive.

The results and recommendations emanating from the evaluation were incorporated into two major reports submitted to the CCOP Project Office entitled "Handling, Storage and Retrieval of Petroleum Data in CCOP Countries" and "Data Base Management Systems Applicable to Petroleum Data Storage and Retrieval in CCOP Countries". In addition, reports on specific evaluations were prepared to provide more detalled recommendations to six of the countries.

In 1980, two more contracts were drawn up between ESCAP and IUGS, calling for a continuation of COGEODATA's consulting services in assisting the individual CCOP countries in the fields of manual document archiving, development of repositories of physical objects, data base, data bank and user data bases construction. The team was also asked to initiate a standardized thesaurus for petroleum data, which would include geographic, physiographic and stratigraphic terms, to develop a standardized data capture format for the creation of a well data file - a prototype file of approximately 300 individual records, and an oil and gas pool data file, to assist 


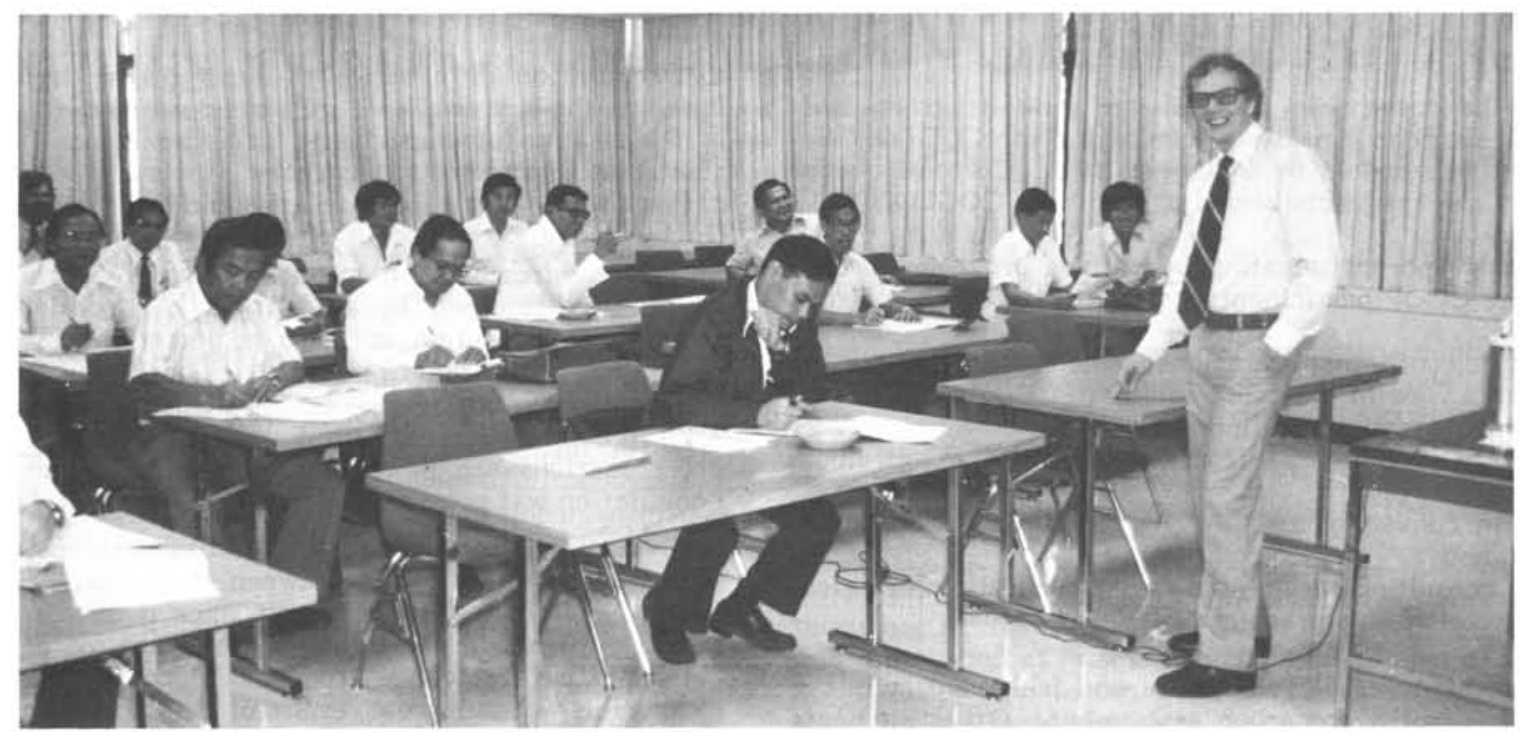

COGEODATA Chairman Dr. Richard Sinding-Larsen (right) running a workshop in

\section{Bangkok.}

in obtaining training facilities in the fields of data management (microfilming, repository management, keywording, indexing, archiving and data bank activities) for professionals in the CCOP countries, and to help organize a workshop on standardization of terminology and formats for energy data.

Between May and July 1980, Jennifer Cook and Allen Clark visited a number of academic, governmental, and private groups in the U.S.A. to seek their assistance in providing training to CCOP member country representatives in petroleum data archiving, handling, and analysis. Among those contacted were: Petroleum Data Systems at the University of Oklahoma in Norman, Petroleum Information Inc. in Denver, Petroleum Abstracts at the University of Tulsa, Oklahoma, Conservation Division of the U.S. Geological Survey in Louisiana and its Geologic Division in Reston, Energy Information Systems of the U.S. Department of the Interior in Washington.

All of these groups agreed, in principle, to assist in training once a specific date and number of participants were determined by the CCOP Program Office. Richard Sinding-Larsen contacted the Norwegian Petroleum Directorate and was able to arrange provisional agreement for training in Stavanger, Norway. A three-to-four week course has been proposed, as follows:

-Petroleum data archiving, data analysis for resource assessment and contract/contractor monitoring data systems ( 4 days);

-Petroleum data abstracting, keywording, and indexing, data archiving ( 3 days);

-Petroleum data handling, oil and gas pool data file, data preparation and file creation ( 3 days);

-Petroleum data handling, well data file, integrated file and analysis system, micrographics ( 3 days);

-Data acquisition and validation relative to monitoring industry activity offshore, seismic data handling and processing, accounting and auditing data activities. Computer applications to petroleum data files, digitizing, and data analysis ( 5 days).

In another major phase of activity, a preliminary thesaurus was developed, using the existing "Exploration and Production Thesaurus" and the "Geographic Thesaurus of the Petroleum Abstracts Group" at the University of Tulsa. In compiling it, the entire thesauras file of Petroleum Abstracts was installed on the U.S. Geological Survey's Honeywell Multics system in Reston, Virginia. Utilizing this system, a sub-set of data items was prepared for discussion at a Workshop held in Manila on standardization of terminology and formats for energy data; it served as the preliminary thesaurus of geographic/geologic terms for the CCOP region.

EPISODES, Vol. 1981, No. 1.
Similarly, preliminary data formats for both an oil and gas pool/field data file and a well data file were compiled from existing data formats (specifically those of the Petroleum Data Systems, Petroleum Information Inc., and PetroConsultants) and modified with respect to the specific reporting aspects of the CCOP countries. These data formats were also submitted at the Manila Workshop as the preliminary formats for both data files.

A major requirement of the fourth ESCAP/IUGS contract was the organization of a joint CCOP/Philippine Bureau of Energy Development Workshop on Petroleum Data Standardization and Formats, and this was organized as noted above in Manila from July 28 to August $1,1980$.

From August 1980 on, consulting services consisted primarily of follow-up visits to Indonesia, Republic of Korea, Malaysia, Philippines and Thailand, initiating data handling and management procedures according to the individual needs of eåch country. Another Workshop, sponsored by CCOP, was conducted in October at the Asian Institute of Technology devoted to Resource Data Handling and attended by 32 people, including representatives from Korea, China, Indonesia, Philippines, Papua New Guinea, Malaysia, Vietnam, and Thailand. This workshop concentrated on the basic computer aspects of dealing with mineral and energy data and bibliographic systems, introducing participants to the tools of file creation, data file application and computer systems. It was designed to give "hands-on" training to working geologists, geophysicists and engineers in data file design and manipulation.
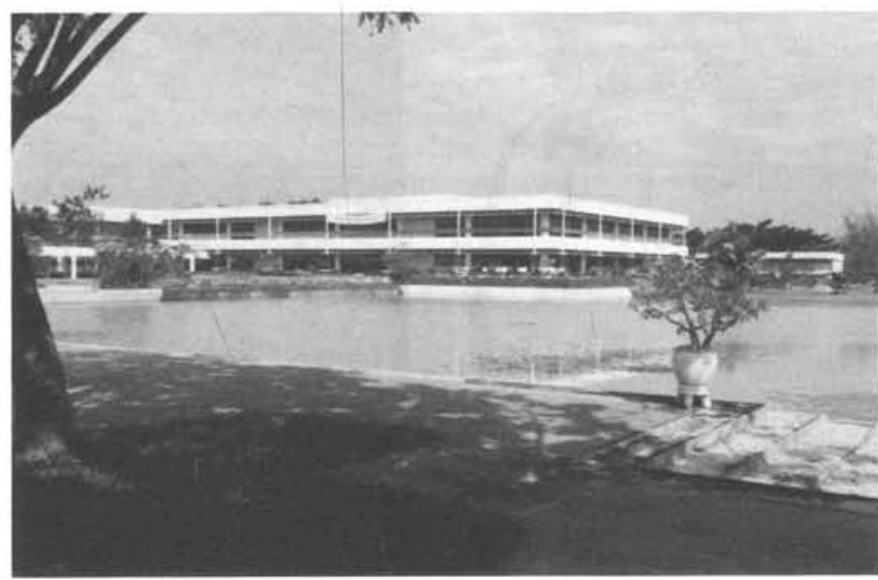

The Asian Institute Technology in Bangkok, Thailand. 


\section{The Future}

Based on the success to date of the joint program, it is anticipated that the consulting services of the COGEODATA team will be requested by CCOP in 1981. Currently under negotiation are contracts aimed at utilizing COGEODATA's expertise in

- coordinating and participating in training programs in data handling for CCOP participants - both in the U.S.A. and in Norway,

- reviewing microfilming operations in the U.S.A., Canada and Europe with a view to providing advice to CCOP countries on their development of microfilming facilities,

- assisting ASCOPE in its efforts to establish a petroleum data center,

- assisting in convening a CCOP Workshop Group on Petroleum Data, and

- providing consulting services to China in the field of petroleum data collection, storage and retrieval.

The joint project has played a vital and fruitful part in the CCOP program of hydrocarbon assessment. Other elements of the overall program include the development of an understanding of the requirements, concepts, and methods of resource assessment through training, demonstration and exchange. This process was started early in 1980 by means of a seminar on "Methods of Assessing Undiscovered Recoverable Hydrocarbon Resources," organized by CCOP in cooperation with the Government of Malaysia, and involved a large number of specialists from industry, government, and academia. A third element in the program is the development of a better understanding of the configuration, stratigraphic sequence, facies distribution, and other parameters of each sedimentary basin that has hydrocarbon resources potential. This will involve several steps for each basin:

\section{ABOUT THE AUTHORS:}

Jennifer L. Cook is a Special Assistant in the U.S. Geological Survey's Office of Energy Resources, World Energy Program. In addition to serving as a consultant to CCOP, she is Project Chief of the Oil-Shale and Potash Resource Assessment Programs of Thailand and the Mineral Resource Data Base of the Philippines. A member of the COGEODATA working group on resource data/assessment programs, she has recently co-edited a Unesco book on resource data handling.

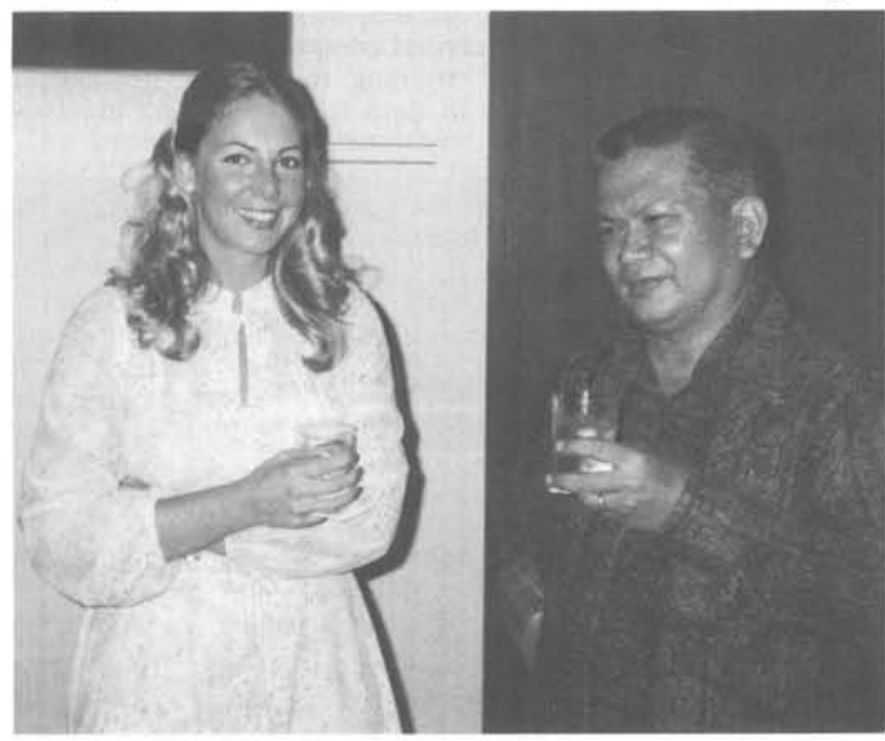

COGEODATA Consultant Jennifer Cook talks to $A$. Johannas, CCOP Program Manager.

EPISODES, Vol. 1981, No. 1. a) Preparation of a series of stratigraphic cross sections based on the best available well and outcrop data;

b) Preparation of isopach and lithofacies maps of selected stratigraphic units or sequences;

c) Preparation of a reference atlas and interpretive report.

Work has already been initiated for the South China Sea, which was selected because it is a "frontier" area for petroleum exploration and must be better understood because of the conflicting claims of countries bordering the Sea. This work was initiated by a workshop held in Honolulu in August 1980 in cooperation with the East-West Center; stratigraphic cross sections are now being prepared, and a preliminary compilation was presented at the workshop.

Plans now call for taking up other basins in sequence. Very likely the Arafura Basin (between Indonesia, Australia, and Papua New Guinea) will be next since it also is a "frontier" basin. All studies will be carried out by local country personnel with guidance from CCOP consultants. To some extent this work uses the results of the stratigraphic correlation and classification work undertaken by IGCP Project 32 on the sedimentary basins in the ESCAP region - and involves preparation of correlation charts and a regional map of the basins.

It is hoped that an evaluation of the hydrocarbon potential of each basin, based on a study of the known distribution of hydrocarbons in relation to the stratigraphy, facies, and architecture of the total basin, will also be undertaken. The extent to which this aspect of the program can be carried out will depend on the agreements reached between each of the countries.

Dr. Allen L. Clark is currently Senior Staff Coordinator for Resource Data/Assessment Programs in the U.S. Geological Survey's Office of International Geology. He serves as a special consultant to CCOP and on the development of resource programs internationally. Prior to this, he served as Chief of the USGS Office of Resource Analysis and Chairman of IGCP Project 98 ("Standards for Computer Applications and Resource Studies"). Dr. Clark serves on the Executive Committee of COGEODATA.

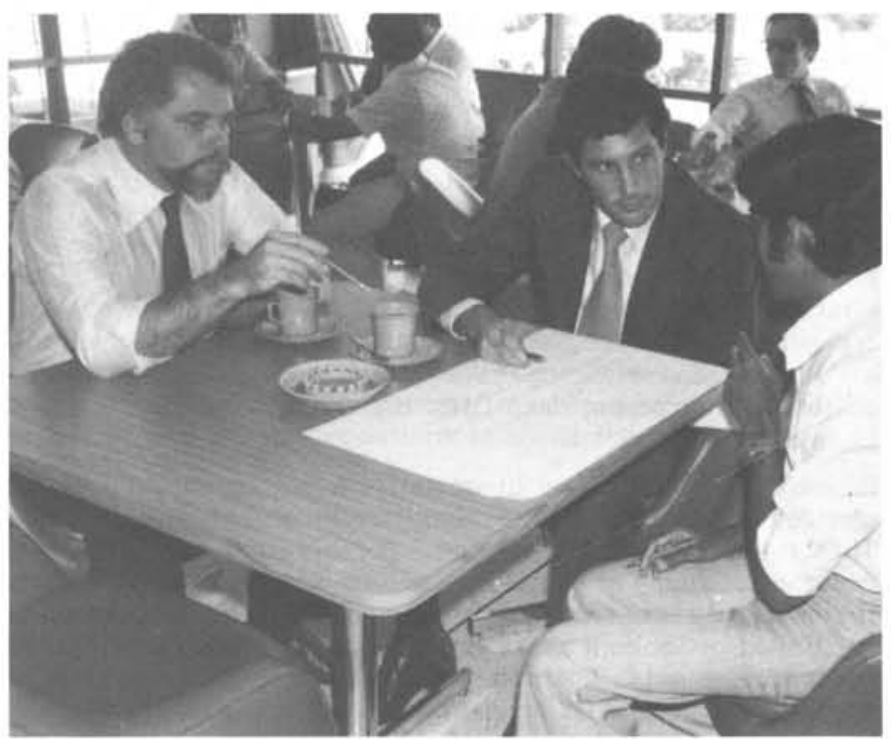

$\mathrm{Dr}$. Allen Clark (left) joins a small discussion group following a workshop session. 